\title{
Costs cloud Korea's synchrotron expansion
}

Pohang, South Korea. South Korea is racing ahead with plans to expand the numbers of beamlines and users for its first synchrotron, based at Pohang University of Science and Technology (Postech). But it remains unclear where all the users will come from and how the operational costs will be shared between the government, Postech and the Pohang Iron and Steel Company (Posco), which backs the project.

The Pohang Accelerator Laboratory (PAL) began routine experiments on its 2-GeV synchrotron, the Pohang Light Source, last year, using two beamlines. The successful completion of the synchrotron in 1994 was a considerable feat as, although it is Korea's first, it is an advanced third-generation machine. The number of users has reached several hundred, according to Won Namkung, director of PAL.

The synchrotron has six beamlines, including one for advanced lithography run by the LG Semicon company. PAL intends to add three new beamlines every year for the next decade with a final target of 40 beamlines and 1,500 to 2,000 users by 2008 , says Namkung. The government has set aside a budget for three new beamlines in 1997 each costing on average about US\$2 million. But it has yet to be resolved how some of the operational costs will be covered.

A large proportion of the initial costs of both Postech and PAL were paid by Posco, the world's second-largest steel-maker (after Nippon Steel of Japan), as part of the company's effort to feed back some of its huge profits to the local community. Almost two-thirds of the \$200-million cost of the light source was paid by the company.

But Posco is beginning to distance itself from the university and PAL. It has paid its last instalment of $\$ 150$ million to the Postech foundation, which will manage an \$25-million fund to help the university with the high running costs of the synchrotron. Costs amount to more than $\$ 20$ million a year if the construction costs of the new beamlines are included.

The government is taking on a larger share of the costs of PAL and it is being operated as a national facility affiliated to Postech for use by scientists throughout Korea. It is also being used by a few overseas scientists. But exactly how operational costs will be shared is still "under negotiation", and it will take time to reach a final decision, says Namkung.

One problem is that Postech is a private university, and it is unprecedented for taxpayers to cover the operating costs, particularly salaries, of a private institution. The university argues that the salaries should be considered part of the operating costs of the national facility, and should be covered by the government. But the government is prepared only to pay half the \$6-million annual bill for the 150 staff at PAL, the university paying the rest. Namkung says PAL refused to agree that a users' fee be introduced to cover some of the costs.

Another challenge facing the laboratory is the recruitment of users. A Korean Synchrotron Users' Association has been set up and now supports more than 200 members, but many more users will be required to justify the laboratory's expansion.

Postech has made some attempts to recruit overseas users. An Australian synchrotron users' group that already has a beamline at Japan's Photon Factory has been courted. But at the end of last year the Australian government decided to put more money into the Photon Factory and a new collaboration with the Advanced Photon Source at Argonne National Laboratory in the United States. The Argonne machine is more powerful than Korea's (see Nature 378, 653; 1995).

There is a handful of users from Japan and Taiwan. But the vast majority are Korean. At a meeting in Seoul earlier this month, science ministers of the Asia-Pacific Economic Cooperation (APEC) forum called for greater sharing of national research facilities in the region. Facilities at Postech were put forward by the Korean government for use by APEC scientists under the forum's planned Advanced Science and Technology Network (see Nature 384, 200: 1996).

But Namkung says that foreign scientists "should not dominate the users' time" and PAL may "impose a cap or designate specific beamlines for international use. Others go further, and suggest - informally - that Korea should not be expected to support the research of scientists from developed countries. 